\title{
Siçanlarda oluşturulan deneysel uterin horn adezyon modelinde düşük molekül ağırlıklı heparin ile oktreotidin etkileri
}

\section{The affect of low molecular weight heparin and octreotide in an experimental uterine horn adhesion model}

\author{
Özgüç Altun, Ahter Tanay Tayyar*, Ahmet Tayyar, Tuncay Özgün, Figen Öztürk, \\ Mehmet Tayyar
}

Kadın Hastalıkları ve Doğum Anabilim Dalı (Dr. Ö. Altun, Dr. A. T. Tayyar, Prof. Dr. M. Tayyar, Doç. Dr. T. Özgün), Patoloji Anabilim Dalı (Prof. Dr. F. Öztürk), Erciyes Üniversitesi Tıp Fakültesi TR-38039 Kayseri Kadın Hastalıkları ve Doğum Kliniği (Dr. A. Tayyar), Niğde Doğan Baran Hastanesi TR-51100 Niğde

\section{Özet}

Amaç. Düşük molekül ağılıklı heparinin postoperatif adezyon önleyici etkinliği daha önce yapılan çeşitli çalışmalarda öne sürülmüştür. Yine Growth hormon üzerinden etki ederek Insulin like growth faktör inhibisyonuyla inflamatuar hücrelerin maturasyon ve migrasyonunu inhibe eden oktreotidin adezyon önleyici etkisi yapılan bazı araştırmalarda gösterilmiştir.Bu çalışmada adezyon gelişiminin farklı basamaklarına etki eden düşük moleküler ağılıklı heparin ve oktreotidin tek başlarına ve kombine kullanımları halinde adezyon oluşumunu önleyici etkilerinin karşılaştırılması amaçlanmaktadır. Yöntem. Çalışmada ağırlığı 250-300 gr arasında değişen 40 adet Wistar-Albino tipi dişi sıçan kullanıldı. Sıçanlar randomize olarak 10'ar sıçanlık grup halinde kontrol ve 3 adet çalışma gruplarına ayrıldı. Adezyon modeli oluşturulduktan sonra kontrol grubu dışındaki diğer 3 gruba düşük moleküler ağıllıklı heparin, oktreotid ve düşük moleküler ağırlıklı heparin ile oktreotid birlikte 14 gün süreyle uygulandı.14 gün sonra sıçanlar letal doz pentobarbital ile öldürüldükten sonra orta hat insizyon ile laparotomi yapılarak adezyon gelişimi değerlendirildi. Bulgular. Makroskopik olarak adezyon şiddeti 3 çalışma grubunda kontrol grubuna göre daha düşük bulundu $(\mathrm{p}<0,05)$. Kombine grupta adezyon şiddeti en az bulundu $(\mathrm{p}<0,05)$. Adezyon yaygınlığı 3 çalışma grubunda da kontrol grubundan az saptandı $(\mathrm{p}<0,05)$. Ancak kombine grup adezyon yaygınlık skoru oktreotid ve düşük moleküler ağılıklı heparin gruplarından farksız bulundu $(\mathrm{p}<0,05)$. Mikroskopik adezyon skorlamasında ise oktreotid ve kombine grupta kontrol grubuna göre belirgin olarak düşüklük izlendi $(p<0,05)$. Sonuç. Oktreotid ve düşük moleküler ağılıklı heparinin postoperatif intraabdominal adezyonları önlemede aynı derecede etkin olduğunu gözlemledik. Kombine kullanımın ise izole düşük moleküler ağırlıklı heparin ve oktreotid kullanımına göre adezyon şiddetini engellemedeki etkinliğinin daha fazla olduğu kanısına vardık.

Anahtar sözcükler: Oktreotid, heparin, peritoneal adezyon

\begin{abstract}
Aim. Previous studies proposed that low molecular weight heparin reduces postoperative adhesion formation. Octreotide reduces the maturation and migration of inflammatory cells by inhibiting insulin like growth factor via growth hormone. Some studies showed that octreotide also reduces postoperative adhesion formation. Low molecular weight heparin and octreotide influence different stages of adhesion formation. The aim of this study was to compare the effect of low molecular weight heparin and octreotide on postoperative adhesion formation either alone or in combination. Methods. The study included 40 Wistar Albino rats weighing between 250-300 g. They were randomised to three study and one control groups each containing 10 rats. After performing an adhesion model except for the control group, low molecular weight heparin, octreotide and low molecular weight heparin plus octreotide groups received the agents for 14 days. The animals were sacrificed by lethal dose pentobarbital at the end of 14 days and a mid-line laparatomy was carried out and abdominal cavity was inspected for the presence of adhesion. Results. In macroscopic evaluation, adhesion severity in the 3 study groups were lower than the control group $(\mathrm{p}<0.05)$. Adhesion severity was lowest in the combined group $(\mathrm{p}<0.05)$. Adhesion
\end{abstract}


extension score of the 3 study group was lower than the control group ( $\mathrm{p}<0.05$ ). But adhesion extension score of the combined group was similar with the octreotide and low molecular weight heparin groups $(p<0.05)$. Microsopic adhesion score of the octreotide and the combined groups were lower than the control group $(\mathrm{p}<0.05)$. Conclusion. Octreotide and low molecular weight heparin are equally effective for prevention of adhesion formation. However, we suggest that combination of octreotide and low molecular weight heparin is more effective than the isolated use of either low molecular weight heparin or octreotide for prevention of adhesion severity.

Keywords: Octreotide, heparin, peritoneal adhesion

Geliş tarihi/Received: 16 Ocak 2012; Kabul tarihi/Accepted: 07 Ağustos 2012

*İletişim adresi:

Dr. Ahter Tanay Tayyar, Kadın Hastalıkları ve Doğum Anabilim Dalı, Erciyes Üniversitesi Tıp Fakültesi, TR-38039 Kayseri. E-posta: drahtertayyar@yahoo.com

\section{Giriş}

Adezyon karın içi organların cerrahiye bağlı olarak ya da peritonit, endometriozis, kemoterapi, radyasyon ve kanser nedeni ile oluşan fibröz bantlarla, kendi aralarında veya karın duvarına yapışmalarıdır.İntraabdominal adezyonların kadın hastalıkları açısından en önemli sonuçları infertilite, kronik pelvik ağrı, disparoni ve ektopik gebeliktir [1]. Abdominal operasyonlardan sonra, intraabdominal adezyon gelişme olasılığı \%67-93 arasındadır [2]. Jinekolojik ve pelvik operasyonlarda bu oran daha yüksektir.Diğer adezyon komplikasyonları arasında reoperasyonlarda operasyon süresinde artma, kanama artış1, komşu organ yaralanması gibi etkileri de mevcuttur [1]. Laparotomiler sonucu oluşan intraabdominal adezyonlar oluşturduğu ikincil problemlere ek olarak ciddi bir ekonomik yükede neden olur [3]. Uygun cerrahi tekniğin dişında intraabdominal girişimlerde oluşabilecek adezyonları önlemede son yıllarda farmakolojik ajanlar ve fizik bariyerler üzerinde yoğun çalışmalar mevcuttur [4]. Kullanılan ajanlar arasında pepsin, steroidler, heparin, aprotinin, dekstran, tripsin, povidon, nonsteroid antiinflamatuarlar, streptokinaz, ürokinaz, vitamin E, kalsiyum kanal blokörleri, oktreotid, kolşisin, antihistaminikler, melatonin, fosfolipid, selüloz, jelatin, amnion mayi, sıvı parafin, gümüş ve altın tabakalar, silikon sayılabilir [5,6]. Ancak tüm bu çalışmalara rağmen postoperatif intraabdominal adezyonları önlemede herkes tarafından kabul görmüş bir yöntem yoktur. Adezyonların önlenmesi amacıyla çok uzun zamandan beri araştırıcılar travma sonucu meydana gelen hemoraji ve bunun koagüle olmasıyla başlayan adezyon kaskatının önlenmesi amaciyla gerek koagulasyonu önleyici heparin gibi ajanlar gerekse fibrinolitikler üzerinde yoğun çalışmalar yürütmektedirler [7]. DMAH, fraksiyone olmamış heparine göre daha spesifik etkilidir. Bu etkisini fraksiyone olmamış heparinin aksine Faktör Xa üzerinden yaptığı inhibisyonla gerçekleştirir. Buna bağlı daha düşük yan etki ve kanama profiline sahip oluğu için çalışmalarda sıklıkla tercih edilen farmakolojik bir üründür. DMAH'in birçok alt tipi bulunmakla birlikte çalışamamızda da tercih ettiğimiz enoksaparin diğer alt tiplere göre daha etkin ve yan etki profili düşük olduğundan klinikte sıklıkla kullanılmaktadır. Oktreotid etkisini, IGF-1 üzerinden gösteren potent bir somatostatin analoğudur. Somatostatin GH inhibitörü olmakla birlikte, oktreotid etkisini daha çok hormonal hücresel iletişimini sağlayan IGF-1 üzerinden göstermektedir. IGF-1 vücutta birçok hücrede mevcut olan büyüme ve maturasyondan sorumlu hücre içi sinyali ileten proteindir. Oktreotid özellikle inflamatuar hücrelerin travma bölegesindeki konsantrasyonunu azaltıp migrasyonunu inhibe etmektedir. Bunun yanında inflamasyonu sağlayan çeşitli büyüme faktölerinin konsantrasyonunuda azalttı̆̆1 çalışmalarda gösterilmiştir [8].

Bu çalışmanın amacı IGF-1 inhibisyonu sağlayan ve inflamatuar hücreler üzerindan etki eden oktreotid ile DMAH'in tek başına veya birlikte kullanımı halinde adezyonu engelleme başarısını araştırmaktır. 


\section{Gereç ve yöntem}

$\mathrm{Bu}$ deneysel çalışma, Erciyes Üniversitesi Tıp Fakültesi (ERÜTF) Hakan Çetinsaya Deneysel ve Klinik Araştırma Merkezinde (DEKAM) da yapıldı. Çalışma öncesinde ERÜTF Etik Kurulu'nun onayı alındı. Çalışmada ağırlığı 250-300 gr arasında değişen 40 adet Wistar-Albino tipi dişi sıçan kullanıldı. Sıçanlar randomize olarak 10'ar sıçanlık kontrol ve 3 adet çalışma grubu olmak üzere toplam 4 gruba ayrıldı. Operasyon öncesi sıçanlar 12 saat aç bırakıldı. Anestezik ajan olarak Ketamin-HCL $(10 \mathrm{mg} / \mathrm{kg})$ intraperitoneal uygulandı. Anestezik madde sonrası sıçanların karın bölgesi traş edilerek, povidon iodin ile boyand. Steril şartlarda $3 \mathrm{~cm}$ 'lik orta hat insizyon ile laparotomi yapıld1. Uterin boynuzların her birinin antimezenterik yüzlerine noktasal tarzda 8-10 adet topuz koter yardımıyla iskemik alanlar oluşturuldu. Bu işlemi takiben her boynuz 4/0 PDS sütür ile karın ön duvar peritonuna sütüre edilerek adezyon modeli oluşturuldu. Cerrahi işlem sonrası fasya periton ile birlikte 4/0 PDS ve cilt 3/0 ipek ile kapatıldı. Cerrahi işlem sonrası gruplar şu şekilde oluşturuldu:

Grup 1 (n=10) Kontrol grubu: Bu gruptaki sıçanlara adezyon oluşturmak için deneysel model oluşturulduktan sonra tedavi uygulanmaksızın karın katları kapatıldı.

Grup 2 (n=10) DMAH grubu: Bu gruptaki sıçanlara adezyon oluşturmak için deneysel model uygulandıktan sonra karın katları kapatılıp 14 gün süreyle $50 \mathrm{U} / \mathrm{kg}$, bir DMAH olan enoksaparin (Clexane, Avantis Farma A.Ş.) intraperitoneal olarak verildi.

Grup 3 (n=10) Oktreotid grubu: Bu gruptaki sıçanlara adezyon oluşturmak için deneysel model uygulandıktan sonra karın katları kapatılıp 14 gün süreyle 10 mikrogram $/ \mathrm{kg}$ i.m. oktreotid (Sandostatin ampul, Novartis A.Ş.) uyguland1.

Grup4 (n=10) Kombine grup: Bu gruptaki sıçanlara adezyon oluşturmak için deneysel model uygulandıktan sonra karın katları kapatılı i.m. 10 mikrogram $/ \mathrm{kg}$ oktreotid ve intraperitoneal $50 \mathrm{U} / \mathrm{kg}$ enoksaparin 14 gün boyunca uyguland.

Postoperatif dönemde 2. ve 3. günlerde kontrol grubundan 1, oktreotid grubundan da 1 sıçan yara yeri dehizyonuna bağlı olarak öldüler. Kontrol grunundan 9, oktreotid grubundan 9,diğer gruplardan 10'ar rat olmak üzere çalışmaya 38 rat ile devam edildi. On dört gün sonra sıçanlar letal doz pentobarbital ile öldürüldükten sonra sol paramedian insizyon ile laparotomi yapılıp adezyon gelişimi değerlendirildi. Bu amaçla adezyon şiddeti Knightly sınıflaması (Tablo 1), yaygınlığı ise Linsky sınıflamasına (Tablo 2) göre skorlanarak öncelikle makroskopik olarak değerlendirildi.

Tablo 1. Adezyon şiddet skorlaması.

\begin{tabular}{ll}
\hline Evre & \multicolumn{1}{c}{ Tanımlama } \\
\hline 0 & Adezyon yok \\
1 & İnce film şeklinde adezyonlar;dokulardan kolaylıkla ayrılabilen ince adezyon \\
2 & Diseksiyon sırasında doku hasarı oluşturmayan gergin adezyon \\
3 & Diseksiyon sırasında serozal doku hasarı oluşturan gergin adezyon \\
4 & Diseksiyon sırasında tam kat doku hasarına yol açan sert adezyon \\
\hline
\end{tabular}

Tablo 2. Adezyon yaygınlık skorlaması.

\begin{tabular}{ll}
\hline Evre & \multicolumn{1}{c}{ Tanımlama } \\
\hline 0 & Adezyon yok \\
1 & Travmatize alanın \%1-25'inden azında adezyon \\
2 & Travmatize alanın \%26-50'sinde adezyon \\
3 & Travmatize alanın \%51-75'inde adezyon \\
4 & Travmatize alanın \%76-100'ünde adezyon \\
\hline
\end{tabular}


Makroskopik değerlendirmeyi takiben adezyon skorlaması için her bir uterin horn karın ön duvar peritonu ile birlikte tam kat patolojik örnekleme için eksize edildi. Sonrasında patolojik piyesler \%10'luk tamponlanmış formol içeren kaplarda fikse edildi. Klasik laboratuar yöntemiyle takibi yapılan piyesler parafin bloklara gömülerek 5 mikrometre kalınlığındaki kesitler lam üzerine alındı. Hematoksilen-Eozin boyası ile boyanarak $1 s ̧ 1 k$ mikroskopisi ile incelendi. Histopatolojik değerlendirme sonrası piyesler mikroskopik derecelendirmeye tabi tutuldu. Bu değerlendirmede Zuhlke'nin mikroskopik adezyon klasifikasyonu kullanıldı (Tablo 3). Veriler ortalama \pm standart hata $(\mathrm{X} \pm \mathrm{SE})$ ve median (min-max) olarak gösterildi. Makroskopik ve histopatolojik değerlerin karşılaştırılmasında Kruskal-Wallis ve Mann-Whitney U testi kullanıldı.İstatistik, Statistical Package for the Social Sciences (SPSS) for Windows (12.0 version) programında yapıldı. $\mathrm{p}<0,05$ değerleri istatistiksel olarak anlamlı kabul edildi.

Tablo 3. Mikroskopik adezyon sınıflaması.

\begin{tabular}{ll}
\hline Evre 1 & Zayıf konnektif doku, zengin hücre, eski ve yeni fibrin, ince retikülin fibriller \\
Evre 2 & Hücreler ve kapiller damarların olduğu konnektif doku, nadir kollajen lifleri \\
Evre 3 & $\begin{array}{l}\text { Daha kalın konnektif doku, nadir hücreler, daha fazla damarlar, nadir elastik ve } \\
\text { düz kas lifleri }\end{array}$ \\
Evre 4 & $\begin{array}{l}\text { Eski kalın granülasyon dokusu, hücreden fakir, serozal tabakaların zor } \\
\text { ayrılması }\end{array}$ \\
\hline
\end{tabular}

\section{Bulgular}

Adezyon yaygınlık ve şiddet skorları her sıçanda mevcut olan iki uterin horn için ayrı ayrı değerlendirildi. Kontrol grubunda 16, DMAH grubunda 15,oktreotid grubunda 12, kombine grupta 11 uterin hornda değişik sayı, şiddet ve yaygınlıkta adezyonlar mevcuttu. Uterin hornlardaki adezyon şiddetlerinin gruplar arası istatistiksel karşılaştırılması Tablo 4'de sunulmuştur. Gruplar arası adezyon yaygınlık skorlarının istatistiksel karşılaştırılması Tablo 5'de sunulmuştur. Gruplar arası total adezyon skorlarının istatistiksel karşılaştırılması Tablo 6'da sunulmuştur.

Tablo 4. Gruplar arası adezyon şiddeti skorları.

\begin{tabular}{lllllll}
\hline Grup & Ortalama & Minimum -Maksimum & $\mathbf{P}^{\mathbf{1}}$ & $\mathbf{P}^{\mathbf{2}}$ & $\mathbf{P}^{\mathbf{3}}$ & $\mathbf{P}^{4}$ \\
\hline Oktreotid & 1,27 & $0,00-3,00$ & $<0,05$ & & $>0,05$ & $<0,05$ \\
DMAH & 1,55 & $1,00-3,00$ & $<0,05$ & $>0,05$ & - & $<0,05$ \\
Kombine & 0,88 & $0,00-2,00$ & $<0,05$ & $<0,05$ & $<0,05$ & - \\
Kontrol & 2,27 & $0,00-4,00$ & - & $<0,05$ & $<0,05$ & $<0,05$ \\
\hline $\mathbf{P}^{1}:$ Kontrol grubu ile diğer grupların karşılaştırılması. & & & \\
$\mathbf{P}^{\mathbf{2}}$ : Oktreotid grubu ile diğer grupların karş1laştırılması. & & & \\
$\mathbf{P}^{\mathbf{3}}$ : DMAH grubu ile diğer grupların karşılaştırılması. & & & \\
$\mathbf{P}^{\mathbf{4}}$ : Kombine grubun diğer gruplar ile karşıllaştırılması. & & & \\
\hline
\end{tabular}

Tablo 5. Gruplardaki adezyon yaygınlık skorları.

\begin{tabular}{|c|c|c|c|c|c|c|}
\hline Grup & Ortalama & Minimum-Maksimum & $\mathbf{P}^{1}$ & $\mathbf{P}^{2}$ & $\mathbf{P}^{3}$ & $\mathbf{P}^{4}$ \\
\hline Oktreotid & 1,01 & $0-2,00$ & $<0,05$ & & $>0,05$ & $>0,05$ \\
\hline DMAH & 1,11 & $0-2,00$ & $<0,05$ & $>0,05$ & & $>0,05$ \\
\hline Kombine & 0,66 & $0-2,00$ & $<0,05$ & $>0,05$ & $>0,05$ & \\
\hline Kontrol & 1,77 & $0-3,00$ & & $<0,05$ & $<0,05$ & $<0,05$ \\
\hline $\begin{array}{l}\mathbf{P}^{1}: \text { Kontr } \\
\mathbf{P}^{2}: \text { Oktrec } \\
\mathbf{P}^{3}: \text { DMAl } \\
\mathbf{P}^{4}: \text { Komb }\end{array}$ & $\begin{array}{l}\text { grubu ile } \\
\text { tid grubu il } \\
\text { I grubu ile } \\
\text { ne grubun }\end{array}$ & $\begin{array}{l}\text { diğer grupların karşılaştır } \\
\text { e diğer grupların karşılaş̧ } \\
\text { liğer grupların karşılaştır } \\
\text { liğer gruplar ile karşılaştı }\end{array}$ & $\begin{array}{l}\text { 1lmasi. } \\
\text { irilmas } \\
\text { 1lmasi. } \\
\text { rilmasi }\end{array}$ & & & \\
\hline
\end{tabular}


Histotalojik değerlendirme mikroskopik adezyon klasifikasyonuna göre yapıldı ve burada konnektif doku kalınlığı, retikülin ve kollajen lifleri, hücre ve kapiller damarlar göz önünde tutuldu. Gruplar arası mikroskobik adezyon skorlarının istatistiksel karşılaştırılması Tablo 7'de sunulmuştur.

Tablo 6. Gruplardaki total adezyon skorları.

\begin{tabular}{|c|c|c|c|c|c|c|}
\hline Grup & Ortalama & Minimum-Maksimum & $\mathbf{P}^{1}$ & $\mathbf{P}^{2}$ & $\mathbf{P}^{3}$ & $\mathbf{P}^{4}$ \\
\hline Oktreotid & 2,28 & $0-4,00$ & $<0,05$ & & $>0,05$ & $>0,05$ \\
\hline DMAH & 2,66 & $0-4,00$ & $<0,05$ & $>0,05$ & & $<0,05$ \\
\hline Kombine & 1,54 & $0-3,00$ & $<0,05$ & $>0,05$ & $<0,05$ & \\
\hline Kontrol & 4,04 & $0-5,00$ & $=$ & $<0,05$ & $<0,05$ & $<0,05$ \\
\hline $\begin{array}{l}\mathbf{P}^{1}: \text { Kontr } \\
\mathbf{P}^{2}: \text { Oktrec } \\
\mathbf{P}^{3}: \text { DMAl } \\
\mathbf{P}^{4}: \text { Komb }\end{array}$ & $\begin{array}{l}\text { grubu il } \\
\text { e grubur }\end{array}$ & $\begin{array}{l}\text { diğer grupların karşılaştır } \\
\text { e diğer grupların karşılaş̧ } \\
\text { liğer grupların karşılaştır } \\
\text { liğer gruplar ile karşılaştı }\end{array}$ & $\begin{array}{l}1 \text { lmas1. } \\
\text { irilmas } \\
\text { rilmasi. }\end{array}$ & & & \\
\hline
\end{tabular}

Tablo 7. Gruplardaki mikroskopik adezyon skorları.

\begin{tabular}{|c|c|c|c|c|c|c|}
\hline Grup & Ortalama & Minimum-Maksimum & $\mathbf{P}^{1}$ & $\mathbf{P}^{2}$ & $\mathbf{P}^{3}$ & $\mathbf{P}^{4}$ \\
\hline Oktreotid & 1,55 & $0,00-3,00$ & $<0,05$ & & $>0,05$ & $<0,05$ \\
\hline DMAH & 1,99 & $1,00-3,00$ & $>0,05$ & $>0,05$ & & $<0,05$ \\
\hline Kombine & 1,05 & $0,00-2,00$ & $<0,05$ & $<0,05$ & $<0,05$ & \\
\hline Kontrol & 2,37 & $1,00-4,00$ & & $<0,05$ & $>0,05$ & $<0,05$ \\
\hline $\begin{array}{l}\mathbf{P}^{1}: \text { Kont } \\
\mathbf{P}^{2}: \text { Okre } \\
\mathbf{P}^{3}: \text { DM } \\
\mathbf{P}^{4}: \text { Kom }\end{array}$ & grubu il & $\begin{array}{l}\text { liğer grupların karşılaştır } \\
\text { diğer grupların karşılaşt } \\
\text { liğer grupların karşılaştır } \\
\text { liğer grupların karşılaştı1 }\end{array}$ & $\begin{array}{l}\text { 1lmas1. } \\
\text { rilmas1. } \\
\text { lmas1. } \\
\text { 1lmas1. }\end{array}$ & & & \\
\hline
\end{tabular}

\section{Tartışma}

Çalışmamızda gruplar arası adezyon şiddetleri karşılaştırıldığında oktreotid, DMAH ve kombine grupta adezyon şiddetlerinin kontrol grubuna göre istatistiksel olarak anlamlı derecede azaldığı saptanmıştır. Oktreotid ve DMAH grupları karşılaştırıldığında istatistiksel olarak anlamlı farklılık mevcut değilken, kombine grubun her iki çalışma grubuna oranla adezyon şiddetini azaltmada daha etkin olduğu istatistiksel olarak tespit edilmiştir. Lai ve Chen [8], Lai ve ark. [9] ratlar üzerinde yapmış oldukları deneysel çalışmalarda oktreotidin adezyon şiddetini kontrol grubuna göre etkin bir şekilde azalttığ 1 tespit edilmiştir. $\mathrm{Bu}$ araştırmalarda değişken oktreotid dozları ve uygulama şekillerine rağmen oktreotidin adezyon şiddetinin engellemesi yönündeki etkinliği ortaya konulmuş̧tur. DMAH'ın adezyon şiddetini azalttığına dair literatürde çeşitli çalışmalar mevcuttur. Çalışmamızda saptadığımız adezyon şiddetinin önlenmesinde DMAH'ın olumlu etkisi mevcut literatür bilgisi ile benzerlik göstermektedir [10-12]. DMAH ve oktreotidin birlikte kullanımına literatürde rastlamadığımızdan adezyon şiddetine bu kombinasyonun olumlu etkisini kıyaslıyamadık Ancak DMAH'ın başka ajanlarla birlikte kullanımıyla adezyon şiddetini daha fazla azalttığına dair yayınlar bulunmaktadır [13-15]. Kombine kullanımın adezyon gelişiminin değişik basamaklarını etkileyerek sinerji oluşturduğunu ve tek başlarına kullanımına oranla adezyon şiddetinin azaltılmasında sinerjistik etkiyle daha faydalı olabileceğini düşünmekteyiz. Çalışmamızda oktreotid, DMAH ve kombine grupta adezyon yaygınlık oranlarının kontrol grubuna göre istatistiksel olarak daha düşük olduğu bulunmuştur.Çalışma grupları kendi aralarında adezyon yaygınlığı yönünden karşılaştırıldığında ise istatistiksel olarak anlamlı farklılık saptanmamıştır (Tablo 5 ). Lai ve Chen [8], Lai ve ark. [9] ratlarda yapmış oldukları deneysel çalışmalarda oktreotid kullanılan ratlarda adezyon yaygınlılığının kontrol grubuna oranla daha düşük olduğunu tespit etmişlerdir. $\mathrm{Bu}$ araştırmaların sonuçları adezyon yaygınlığının engellenmesi yönünden bizimkiyle benzerlik göstermektedir. 
DMAH'ın adezyon yaygınlığının azaltılmasına yönelik olumlu etkileri daha önce yapılan değişik çalışmalarda gösterilmiştir $[10,11]$. Bu araştırmaların bulguları adezyon yaygınlığının önlenmesi açısından bizimkiyle paralellik göstermektedir. Total adezyon skorları karşılaştırıldığında çalışma gruplarımızda kontrol grubuna göre istatistiksel olarak daha düşük adezyon skoruna sahip oldukları tespit edilmiştir. Oktreotid grubu ile DMAH grubu arasında total adezyon skorları yönünden anlamlı farklılık izlenmemiştir. Kombine grupta, DMAH grubuna göre total adezyon skorunun daha düşük olduğu tespit edilmişken, oktreotid grubuyla karşılaş̧tırıldığında istatistiksel olarak anlamlı farklılık saptanmamıştır. Alataş ve ark. [16] ile Çolak ve ark. [17]'nın oktreotid ile yapmış oldukları çalışmalarda ratlarda adezyon modeli olarak çekal ablazyon ile oluşturulmuş,total adezyon skorunu değerlendiklerinde kontrol grubuna göre adezyonların engellenmesinde oktreotidin yüksek etkinlikte olduğunu tespit etmişlerdir. Kullanılan adezyon modeli bu araştırmalarda farklı olsada sonuçları bizim çalışmamızdakine benzerlik göstermektedirler. DMAH'ın total adezyon skorlarını azaltmadaki etkinliği çalışmalarda gösterilmiştir [10-12]. Bu çalışmaların sonuçları bizimkiyle benzerlik göstermektedir. Çalışmamızda kombine kullanımın izole DMAH kullanımına göre total adezyon skorunu belirgin olarak azalttığı tespit etmekle birlikte,oktreotid grubu ile istatistiksel olarak anlamlı farklılık izlenmemiştir. Literatür taramamızda iki ajanın kombine kullanımı ile ilgili çalışma bulunamadığından karşılaştırma yapılamamıştır. Ancak, DMAH'ın oktreotid ile birlikte kullanımıyla sinerjistik etki oluştuğunu ve total adezyon skorunu azalttığını düşünmekteyiz. Araştırmamızda, gruplar arası mikroskobik adezyon skorlaması değerlendirildiğinde oktreotid grubu ve kombine grupta mevcut skorlar kontrol grubuna göre istatistiksel olarak anlamlı derecede düşük iken, DMAH ve kontrol grubu arasında istatistiksel farklılık tespit edilmemiştir. Kombine grupta mikroskopik adezyon skorları diğer tüm gruplara göre istatistiksel olarak anlamlı derecede düşük bulunmuştur. Literatür taramamızda oktreotidin mikroskopik adezyon skorlamasını araştıran çalışma bulunamamıştır. Çalışmamızda makroskopik olarak tespit etmiş olduğumuz oktreotid etkinliği, mikroskopik olarakta desteklenmiştir. Buda DMAH ve oktreotidin birbirinin etkinliğini artırdığının hücresel aşamada da kanıtlanması açısından önemlidir. DMAH grubunda, mikroskopik adezyon skoru diğer gruplar ile karşılaştırıldığında istatistiksel olarak anlamlı farklılık olmadığı sonucuna varılmıştır. Sortini ve ark. [18] ise yaptıkları deneysel çalışmada bu skoru kontrol grubuna nazaran daha düşük bulmuşlardır. Araştırmamızda makroskopik olarak kontrol grubuna göre üstünlüğü bulunan DMAH'ın, mikroskopik olarak desteklenmemesi patolojik inceleme için alınan spesmenlerin yetersizliği, adezyon bölegelerinden daha fazla örnekleme yapılması gerekliliğine bağlı olabileceğini düşündürmektedir.

Sonuç olarak, yapmış olduğumuz deneysel çalışmada, DMAH ve oktreotidin birlikte kullanımının adezyon şiddetinin azaltılmasında, mikroskopik olarak ajanların tek başına kullanımına göre belirgin üstünlük taşıdığı tespit edildi. Adezyon yaygınlığı ve total adezyon skoru olarak değerlendirildiğinde ise kontrol grubuna göre yine üstünken, oktreotid grubuna göre istatistiksel olarak anlamlı farkı olmadığı saptanmıştır. Ancak adezyon şiddetinin azaltılması önemlidir, çünkü; cerrahi sırasında ortaya çıkan dokular arasındaki derin adezyonlar ortadan kalkmaktadır. Bu sayede derin invazyon gösteren adezyonlar azaltılarak, organ hasarının engellenebileceği ve cerrahi morbiditenin en aza indirilebileceği kanısındayız.

\section{Kaynaklar}

1. Practice Committee of American Society for Reproductive Medicine in collaboration with Society of Reproductive Surgeons. Pathogenesis, consequences, and control of peritoneal adhesions in gynecologic surgery. Fertil Steril 2008; 90: S144-9.

2. Liakakos T, Thomakos N, Fine PM, Dervenis C, Young RL. Peritoneal adhesions: etiology, pathophysiology, and clinical significance. Recent advances 
in prevention and management. Dig Surg 2001; 18: 260-73.

3. Coleman MG, McLain AD, Moran BJ. Impact of previous surgery on time taken for incision and division of adhesions during laparotomy. Dis Colon Rectum 2000; 43: 1297-9.

4. Remah MK. Prevention of postoperative peritoneal adhesions. Eur J Obstet Gynecol Reprod Biol 2010: 150; 111-8.

5. Nehéz L, Vödrös D, Axelsson J, Tingstedt B, Lindman B, Andersson R. Prevention of postoperative peritoneal adhesions: Effects of lysozyme, polylysine and polyglutamate versus hyaluronic acid. Scand J Gastroenterol 2005; 40: 111823.

6. Metwally M, Watson A, Lilford R, Vandekerckhove P. Fluid and pharmacological agents for adhesion prevention after gynaecological surgery. Cochrane Database Syst Rev 2006: CD001298.

7. Arıkan S, Adas G, Barut G, Toklu AS, Kocakuşak A, Uzun H, Kemik O, Daduk Y, Aydin S, Purisa S. An evaluation of low molecular weight heparin and hyperbaric oxygen treatment in the prevention of intra-abdominal adhesions and wound healing. Am J Surg 2005; 189: 155-2.

8. Lai HS, Chen Y. Effect of octreotide on postoperative intraperitoneal adhesions in rats. Scand J Gastroenterol 1996: 31: 678-81.

9. Lai HS, Chen Y, Chang KJ, Chen WJ. Effects of octreotide on epidermal growth factor receptor, tissue plasminogen activator, and plasminogen activator inhibitor during intraperitoneal adhesion formation. J Gastroenterol 2003; 38: 555-60.

10. Türkçapar AG, Ozarslan C, Erdem E, Bumin C, Erverdi N, Kutlay J. The effectiveness of low molecular weight heparin on adhesion formation in experimental rat model. Int Surg 1995; 80: 92-4.

11. Kumar S, Wong PF, Leaper DJ. Intra-peritoneal prophylactic agents for preventing adhesions and adhesive intestinal obstruction after non-gynaecological abdominal surgery. Cochrane Database Syst Rev 2009; 21: CD005080.

12. Kement M, Censur Z, Oncel M, Buyukokuroglu ME, Gezen FC. Heparin for adhesion prevention: Comparison of three different dosages with Seprafilm in a murine model. Int J Surg 2011; 9: 255-8.

13. Şahin Y, Sağlam A. Synergistic effects of carboxymethylcellulose and low molecular weight heparin in reducing adhesion formation in the rat uterine horn model. Acta Obstet Gynecol Scand 1994; 73: 70-3.

14. Tayyar M, Turan R, Ayata D. The use of amniotic membrane plus heparin to prevent postoperative adhesions in the rabbit. Tokai J Exp Clin Med 1993; 18: 57-60.

15. Tayyar M, Başbuğ M. The effects of intraperitoneal piroxicam and low molecular weight heparin in prevention of adhesion reformation in rat uterine horn. Res Exp Med 1999; 198: 269-75.

16. Alatas E, Günal $\mathrm{O}$, Alatas $\mathrm{O}$, Colak O. Octreotide prevents postoperative adhesion formation by suppressing peritoneal myeloperoxidase activity. Hepatogastroenterology 2000; 47: 1034-6.

17. Çolak T, Dağ A, Türkmenoğlu O, Polat A, Comelekoğlu U, Bağdatoğlu O, Polat G, Akca T, Sucullu I, Aydın S. The effect of octreotide on healing of injured colonic anastomosis with immediate postoperative intraperitoneal administration of 5-Fluorouracil. Dis Colon Rectum 2007; 50: 660-9.

18. Sortini D, Feo CV, Maravegias K, Carcoforo P, Pozza E, Liboni A, Sortini A. Role of peritoneal lavage in adhesion formation and survival rate in rats: An experimental study. J Invest Surg 2006; 19: 291-7. 